\title{
EFISIENSI PENGGUNAAN TEMPAT TIDUR DI RUANG RAWAT INAP BERDASARKAN GRAFIK BARBER JOHNSON DI RSUD DR. PIRNGADI MEDAN
}

\author{
Valentina \\ Dosen Prodi D-III Perekam Dan Infokes Imelda, Jalan Bilal Nomor 52 Medan
}

E-mail: valentinave89@gmail.com

\begin{abstract}
ABSTRAK
Salah satu indikator yang harus diperhatikan oleh rumah sakit untuk meningkatkan pelayanan rumah sakit adalah efisiensi pelayanan rawat inap, terutama pada pemanfaatan tempat tidur. Dalam memantau tingkat efisiensi penggunaan tempat tidur ruang perawatan dapat dilihat dari grafik Barber Johnson berdasarkan hasil perhitungan Bed Occupancy Ratio (BOR), Average Length Of Stay (AvLOS), Turn Over Internal (TOI), Bed Turn Over (BTO). RSUD Dr. Pirngadi Medan memiliki jumlah tempat tidur di ruang rawat inap sebanyak 482 buah dan jumlah pasien sebanyak 11.558 pasien pada tahun 2018. Tujuan penelitian adalah mengetahui efisiensi penggunaan tempat tidur di ruang rawat inap berdasarkan grafik Barber Johnson. Jenis penelitian ini adalah deskriptif. Subyek penelitian adalah rekapitulasi sensus harian rawat inap di RSUD Dr. Pirngadi Medan Tahun 2018. Informan yaitu satu orang petugas rekam medis bagian pelaporan. Penelitian dilakukan pada bulan Februari sampai Agustus 2019. Pengumpulan data menggunakan teknik wawancara dan observasi. Hasil penelitian diperoleh perhitungan BOR tahun 2018 yaitu 37,50\%, AvLOS yaitu 5,36 hari, TOI yaitu 9,51 hari dan BTO yaitu 24,00 kali. Nilai AvLOS sudah ideal karena memenuhi standar Barber Johnson tetapi nilai BOR, TOI dan BTO belum ideal karena belum memenuhi standar disebabkan karena jumlah pasien yang sedikit. Disarankan kepada petugas rekam medis di RSUD Dr. Pirngadi Medan agar memperhatikan kembali rumus yang digunakan dalam menghitung nilai BOR, AvLOS, TOI dan BTO serta membuat grafik Barber Johnson secara rutin setiap tahun sehingga dapat meningkatkan efesiensi dan efektifitas penggunaan tempat tidur di ruang rawat inap serta sebagai strategi perencanaan di tahun berikutnya.
\end{abstract}

Kata Kunci : Tempat Tidur, Grafik, Barber Johnson.

\section{PENDAHULUAN}

Rumah sakit adalah institusi pelayanan kesehatan yang menyelenggarakan pelayanan kesehatan perorangan secara paripurna yang menyediakan pelayanan rawat inap, rawat jalan dan gawat darurat (Kepmenkes, 2010).

Salah satu indikator yang harus diperhatikan oleh rumah sakit untuk meningkatkan pelayanan rumah sakit adalah efisiensi pelayanan rawat inap, terutama pada pemanfaatan tempat tidur. Jumlah tempat tidur yang digunakan dalam pelayanan rawat inap berpengaruh pada tingkat efisiensi penggunaan tempat tidur di rumah sakit tersebut.

Tingkat efisiensi penggunaan tempat tidur di rumah sakit diperoleh berdasarkan indikator pelayanan rumah sakit yaitu Bed Occupancy Ratio (BOR), Average Length Of Stay (AvLOS), Turn Over Internal (TOI), Bed Turn Over (BTO). BOR adalah persentase tempat tidur terisi. AvLOS adalah rata-rata lama pasien dirawat. TOI adalah rata-rata waktu luang tempat tidur. BTO adalah produktifitas tempat tidur. Nilai standar ideal untuk keempat parameter tersebut adalah BOR 75\% - 85\%, AvLOS 3 - 
12 hari, TOI 1 - 3 hari dan BTO 30 kali (Rustiyanto, 2010).

Grafik Barber Johnson bisa dimanfaatkan untuk membandingkan tingkat efisiensi penggunaan tempat tidur dari suatu unit, rumah sakit maupun bangsal dari waktu ke waktu dalam periode tertentu, memonitor perkembangan pencapaian target efisiensi penggunaan tempat tidur yang telah ditentukan dalam suatu periode tertentu, membandingkan tingkat efisiensi penggunaan tempat tidur antar unit dalam periode tertentu, dan mengecek kebenaran laporan hasil perhitungan empat parameter efisiensi penggunaan tempat tidur yaitu jika keempat garis bantunya berpotongan di satu titik berarti laporan hasil perhitungan tersebut benar (Sudra, 2010).

Penelitian Jannah (2016) di RSUD Tipe

B Kota Makassar Tahun 2016 diperoleh hasil perhitungan indikator pelayanan untuk nilai BOR di RSUD Labuang Haji sebesar 45,3\%, RSUD Kota Makassar sebesar 66,5\% dan RSUD Haji Makassar sebesar $60,2 \%$ belum memenuhi standar Internasional yakni $75-85 \%$. Nilai LOS dari ketiga rumah sakit tersebut sudah memenuhi standar. Nilai TOI untuk RSUD Labuang Haji Makassar sebesar 5 hari belum sesuai dengan standar ideal sedangkan nilai TOI di RSUD Kota Makassar sebesar 1 hari dan RSUD Haji Makassar sebesar 2 hari sudah sesuai standar yaitu 1-3 hari. Penilaian efisiensi penggunaan tempat tidur menggunakan grafik Barber Johnson belum efisien karena titik Barber Johnson berada diluar daerah efisiensi.

Selain itu, penelitian Pretty (2018) di RSUD Doloksanggul menunjukkan bahwa efisiensi pelayanan rawat inap belum efisien dikarenakan jumlah tempat tidur tidak sesuai dengan jumlah pasien yang dirawat dan hari rawatan yang rendah dimana nilai BOR 15,21\%, AvLOS 2,5 hari, TOI 13,96 hari dan BTO 22,16 kali.

Hasil survey awal di RSUD Dr. Pirngadi Medan memiliki jumlah tempat tidur di ruang rawat inap sebanyak 482 buah dan jumlah pasien sebanyak 11558 pasien pada tahun 2018. Nilai BOR di RSUD Dr. Pirngadi Medan pada tahun 2017 adalah 52,19\%, AvLOS 5,83 hari, TOI 6,78 hari dan BTO 25,75 kali. Jika dilihat berdasarkan nilai ideal menurut Barber Johnson, maka nilai BOR belum ideal, nilai AvLOS sudah ideal, nilai TOI belum ideal dan BTO belum ideal sehingga penggunaan tempat tidur pada tahun 2017 masih belum efisien.

\section{Perumusan Masalah}

Bagaimana efisiensi penggunaan tempat tidur di ruang rawat inap berdasarkan grafik Barber Johnson di RSUD Pirngadi Medan tahun 2018?

\section{Tujuan Penelitian}

Tujuan penelitian adalah untuk mengetahui efisiensi penggunaan tempat tidur di ruang rawat inap berdasarkan grafik Barber Johnson di RSUD Pirngadi Medan tahun 2018.

\section{Manfaat Penelitian}

1. Bagi Rumah Sakit

Sebagai bahan masukan, evaluasi dan strategi bagi rumah sakit dalam perencanaan penggunaan tempat tidur di ruang rawat inap berdasarkan grafik Barber Johnson.

2. Bagi Intitusi Pendidikan

Penelitian ini diharapkan dapat digunakan sebagai bahan referensi dan pengembangan ilmu pengetahuan dalam bidang rekam medis.

\section{METODE}

\section{Jenis Penelitian}

Jenis penelitan yang digaunakan adalah deskriptif.

\section{Waktu Penelitian}

Waktu penelitian dilakukan pada bulan Februari sampai Agustus 2019.

\section{Tempat Penelitian}

Tempat penelitian ini dilakukan di RSUD Pirngadi Medan yang berlokasi di Jl. Prof. H. M. Yamin SH No. 47, Perintis, Medan Timur. 
Subyek

Subyek dalam penelitian ini adalah rekapitulasi sensus harian rawat inap di RSUD Dr. Pirngadi Medan pada tahun 2018.

\section{Informan}

Informan adalah orang yang dapat memberikan informasi yang diperlukan. Informan dalam penelitian ini adalah satu orang petugas rekam medis bagian pelaporan di RSUD Dr. Pirngadi Medan.

\section{Instrumen Penelitian}

Instrumen yang digunakan dalam penelitian ini adalah lembar observasi dan pedoman wawancara.

\section{Cara Pengumpulan Data}

Cara pengumpulan data yang digunakan adalah observasi, dimana peneliti melakukan pengamatan langsung dengan mencatat data yang dibutuhkan dalam penelitian. Sedangkan wawancara dilakuakn kepada petugas rekam medis di bagian pelaporan.

Sumber data dalam penelitian ini adalah data primer dan data sekunder. Data primer yaitu hasil wawancara yang dilakukan kepada petugas pelaporan. Data sekunder yaitu berupa data rekapitulasi sensus harian rawat inap tahun 2018.

\section{Analisis Data}

Analisis data dilakukan secara deskriptif yaitu membuat gambaran datadata yang terkumpul dengan menggunakan grafik Barber Johnson yang terdiri dari empat parameter yaitu BOR, AvLOS, TOI, BTO. Dari grafik tersebut dapat diketahui efisiensi penggunaan tempat tidur di ruang rawat inap RSUD Dr. Pirngadi Medan.

\section{HASIL}

Data yang digunakan untuk menghitung indikator BOR, AvLOS, TOI dan BTO adalah data rekapitulasi sensus harian rawat inap yang tertuang pada tabel berikut:
Tabel 1. Rekapitulasi Sensus Harian Rawat Inap RSUD Dr. Pirngadi Medan pada Tahun 2018.

\begin{tabular}{rrrrrr}
\hline No & Ruangan & $\begin{array}{c}\text { Jumlah } \\
\text { Tempat } \\
\text { Tidur }\end{array}$ & $\begin{array}{c}\text { Jumlah } \\
\text { Hari } \\
\text { Perawatan }\end{array}$ & $\begin{array}{c}\text { Jumlah } \\
\text { Lama } \\
\text { Dirawat }\end{array}$ & $\begin{array}{c}\text { Jumlah } \\
\text { Pasien } \\
\text { Keluar } \\
\text { Hidup + } \\
\text { Mati }\end{array}$ \\
\hline & VIP & & & & \\
\hline 1 & Raflesia & 11 & 85 & 56 & 7 \\
\hline 2 & Anggrek 1 & 5 & 521 & 425 & 81 \\
\hline 3 & Anggrek 2 & 5 & 237 & 236 & 46 \\
\hline 4 & Dahlia 2 & 4 & 8 & 18 & 2 \\
\hline & KELAS I & & & & \\
\hline
\end{tabular}

\begin{tabular}{rlrrrr}
\hline & KELAS I & & & & \\
\hline 1 & Anggrek 1 & 10 & 2.937 & 2688 & 532 \\
\hline 2 & Anggrek 2 & 6 & 1.440 & 1501 & 263 \\
\hline 3 & Raflesia & 11 & 1.833 & 1684 & 325 \\
\hline 4 & Mawar & 30 & 4.126 & 3713 & 705 \\
\hline 5 & Tulip 1 & 8 & 707 & 529 & 132 \\
\hline 6 & Tulip 2 & 15 & 515 & 624 & 166 \\
\hline 7 & Dahlia 1 & 12 & 3.438 & 3270 & 566 \\
\hline 8 & Dahlia 2 & 10 & 506 & 392 & 57 \\
\hline
\end{tabular}

\section{KELAS II}

\begin{tabular}{rlrrrr}
\hline 1 & Tulip 1 & 20 & 1.645 & 1.336 & 308 \\
\hline 2 & Tulip 2 & 24 & 791 & 707 & 183 \\
\hline 3 & Tulip 3 & 22 & 3.228 & 2.860 & 590 \\
\hline 4 & Dahlia 2 & 17 & 3.113 & 3.015 & 648 \\
\hline 5 & RRG & 8 & 522 & 677 & 73 \\
\hline & KELAS III & & & & \\
\hline 1 & Melati 1 & 20 & 2.810 & 2.857 & 590 \\
\hline 2 & Melati 2 & 14 & 1.508 & 1.808 & 254 \\
\hline 3 & Melati 3 & 20 & 2.671 & 2.604 & 467 \\
\hline 4 & Kenanga 1 & 24 & 3.973 & 4.131 & 614 \\
\hline 5 & Asoka 1 & 24 & 5.089 & 4.808 & 857 \\
\hline 6 & Asoka 2 & 24 & 5.173 & 5.258 & 958 \\
\hline 7 & Tanjung 1 & 12 & 1.401 & 1.241 & 253 \\
\hline 8 & Tanjung 2 & 12 & 1.234 & 797 & 271 \\
\hline 9 & Flamboyan & 21 & 3.461 & 3.001 & 436 \\
\hline 10 & Matahari & 20 & 1.335 & 990 & 249 \\
\hline 11 & Tulip 2 & 12 & 1.769 & 1.883 & 595 \\
\hline & RUANGAN KHUSUS & & & \\
\hline 1 & ICCU & 16 & 2.763 & 2.548 & 504 \\
& Dewasa & & & & \\
\hline 2 & ICCU & 6 & 513 & 159 & 57 \\
\hline 3 & Perinatologi & 21 & 3.584 & 3.468 & 316 \\
\hline 4 & HDU & 4 & 1.273 & 955 & 167 \\
\hline 5 & Unit Stroke & 6 & 939 & 551 & 106 \\
\hline 6 & IMZ & 8 & 813 & 1.246 & 189 \\
\hline & IOTAL & $\mathbf{4 8 2}$ & $\mathbf{6 5 . 9 6 1}$ & $\mathbf{6 2 . 0 3 6}$ & $\mathbf{1 1 . 5 6 7}$ \\
\hline & Tabe 1 & ran & &
\end{tabular}

Tabel 1 menunjukkan bahwa RSUD

Dr. Pirngadi Medan pada tahun 2018 memiliki jumlah tempat tidur sebanyak 482 buah, jumlah hari perawatan sebanyak 65.961 hari, jumlah lama dirawat sebanyak 62.036 hari, jumlah pasien keluar 
(Hidup+Mati) sebanyak 11.562 pasien. Berdasarkan data diatas dapat diketahui hasil perhitungan BOR, AvLOS, TOI dan BTO di RSUD Dr. Pirngadi Medan tahun 2018 pada tabel berikut.

Tabel 2. Hasil perhitungan BOR, AvLOS, TOI dan BTO di Ruang Rawat Inap RSUD Dr. Pirngadi Medan Tahun 2018.

\begin{tabular}{|c|c|c|c|c|c|}
\hline No & Ruangan & BOR & AvLOS & TOI & BTO \\
\hline \multicolumn{6}{|c|}{ VIP } \\
\hline 1 & Raflesia & 2,09 & 8 & 561,58 & 0,64 \\
\hline 2 & Anggrek 1 & 28,6 & 5,25 & 16,09 & 16,2 \\
\hline 3 & Anggrek 2 & 13 & 5,13 & 34,52 & 9,2 \\
\hline 4 & Dahlia 2 & 0,5 & 9 & 726,35 & 0,5 \\
\hline \multicolumn{6}{|c|}{ KELAS I } \\
\hline 1 & Anggrek 1 & 80,5 & 5,05 & 1,34 & 53,2 \\
\hline 2 & Anggrek 2 & 65,83 & 5,71 & 2,85 & 43,83 \\
\hline 3 & Raflesia & 45,64 & 5,18 & 6,72 & 29,55 \\
\hline 4 & Mawar & 37,67 & 5,27 & 9,68 & 23,5 \\
\hline 5 & Tulip 1 & 24,25 & 4,01 & 16,76 & 16,5 \\
\hline 6 & Tulip 2 & 9,4 & 3,76 & 29,88 & 11,07 \\
\hline 7 & Dahlia 1 & 78,5 & 5,78 & 1,66 & 47,17 \\
\hline 8 & Dahlia 2 & 13,9 & 6,88 & 55,13 & 5,7 \\
\hline \multicolumn{6}{|c|}{ KELAS II } \\
\hline 1 & Tulip 1 & 22,55 & 4,34 & 18,36 & 15,4 \\
\hline 2 & Tulip 2 & 9,04 & 3,86 & 43,54 & 7,63 \\
\hline 3 & Tulip 3 & 40,18 & 4,85 & 8,14 & 26,82 \\
\hline 4 & Dahlia 2 & 50,18 & 4,65 & 4,77 & 38,12 \\
\hline 5 & RRG & 17,88 & 9,27 & 32,85 & 9,13 \\
\hline \multicolumn{6}{|c|}{ KELAS III } \\
\hline 1 & Melati 1 & 38,5 & 4,84 & 7,61 & 29,5 \\
\hline 2 & Melati 2 & 29,5 & 7,12 & 14,18 & 18,14 \\
\hline 3 & Melati 3 & 36,6 & 5,58 & 9,91 & 23,35 \\
\hline 4 & Kenanga 1 & 45,33 & 6,73 & 7,80 & 25,58 \\
\hline 5 & Asoka 1 & 58,08 & 5,61 & 4,28 & 35,71 \\
\hline 6 & Asoka 2 & 59,04 & 5,49 & 3,75 & 39,92 \\
\hline 7 & Tanjung 1 & 32 & 4,91 & 11,77 & 21,08 \\
\hline 8 & Tanjung 2 & 28,17 & 2,94 & 11,61 & 22,58 \\
\hline 9 & Flamboyan & 45,14 & 6,88 & 9,64 & 20,76 \\
\hline 10 & Matahari & 18,3 & 3,98 & 23,95 & 12,45 \\
\hline 11 & Tulip 2 & 40,42 & 3,16 & 4,39 & 49,58 \\
\hline \multicolumn{6}{|c|}{ RUANGAN KHUSUS } \\
\hline 1 & $\begin{array}{l}\text { ICCU } \\
\text { Dewasa }\end{array}$ & 47,31 & 5,06 & 6,11 & 31,5 \\
\hline 2 & ICCU & 23,5 & 2,79 & 29,39 & 9,5 \\
\hline 3 & Perinatologi & 46,76 & 10,97 & 12,91 & 15,05 \\
\hline 4 & $\mathrm{HDU}$ & 87,25 & 5,72 & 1,11 & 41,75 \\
\hline 5 & Unit Stroke & 42,83 & 5,20 & 11,81 & 17,67 \\
\hline 6 & IMZ & 27,88 & 6,59 & 11,14 & 23,63 \\
\hline & TOTAL & $\mathbf{3 7 , 5 0}$ & 5,36 & $\mathbf{9 , 5 1}$ & 24,00 \\
\hline
\end{tabular}

Berdasarkan hasil tersebut dapat diketahui nilai indikator BOR, AvLOS, TOI dan BTO setiap ruang rawat inap. Nilai
BOR di RSUD Dr. Pirngadi Medan pada tahun 2018 adalah 37,50\%. Nilai AvLOS di RSUD Dr. Pirngadi Medan pada tahun 2018 adalah 5,36 hari. Nilai TOI di RSUD Dr. Pirngadi Medan pada tahun 2018 adalah 9,51 hari. Nilai BTO di RSUD Dr. Pirngadi Medan pada tahun 2018 adalah 24,00 kali.

Penentuan garis BOR, AvLOS, TOI dan BTO dilakukan dengan langkah-langkah sebagai berikut:

1. Buat garis bantu BOR $37,50 \%$ :

Titik bantu AvLOS $=($ nilai BOR / 10 $)=$ $(37,50 / 10)=3,75$

Titik bantu TOI $=(10-$ nilai AvLOS $)=$ $(10-3,75)=6,25$

2. Buat garis bantu BTO 24,00 kali :

Nilai AvLOS dan TOI sama

Titik bantu $=$ (jumlah hari dalam periode / nilai $\mathrm{BTO})=365 / 24,00=15,21$

3. Garis $\mathrm{AvLOS}=5,36$

4. Garis $\mathrm{TOI}=9,51$

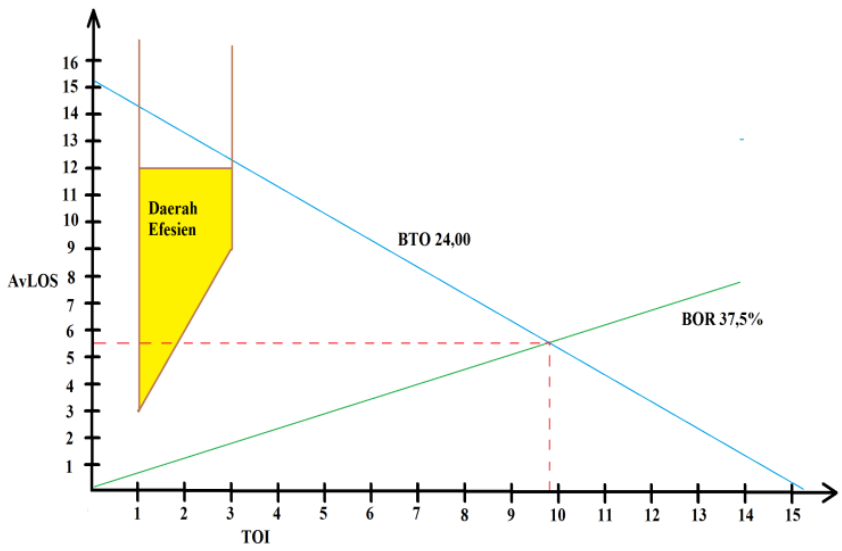

\section{Gambar 1. Grafik Barber Johnson RSUD Pirngadi Medan Tahun 2018}

Gambar 1 menunjukkan bahwa penggunaan tempat tidur di RSUD Dr. Pirngadi Medan belum efisien karena titik Barber Johnson berada di luar daerah efisiensi.

\section{PEMBAHASAN}

Berdasarkan hasil penelitian yang dilakukan dapat diketahui bahwa penggunaan tempat tidur di ruang rawat inap RSUD Dr. Pirngadi Medan pada tahun 2018 belum efisien.

Nilai BOR pada tahun 2018 di RSUD Dr. Pirngadi Medan pada tahun 2018 adalah 
$37,50 \%$. Hasil tersebut menunjukkan bahwa nilai BOR masih rendah dan belum efisien karena belum memenuhi standar yang telah ditentukan yaitu $75-85 \%$. Apabila BOR semakin rendah berarti semakin sedikit tempat tidur yang digunakan dan sedikit pula pasien yang dilayani. Jumlah pasien yang sedikit ini bisa menimbulkan kesulitan pendapatan bagi pihak rumah sakit. Apabila BOR semakin tinggi berarti semakin banyak pasien yang dilayani dan semakin berat pula beban kerja tim medis. Akibatnya, pasien bisa kurang mendapat pelayanan yang dibutuhkan dan kemungkinan infeksi nosokomial juga meningkat (Sudra, 2010).

Nilai AvLOS di RSUD Dr. Pirngadi Medan pada tahun 2018 adalah 5,36 hari. Hasil tersebut menunjukkan bahwa nilai AvLOS sudah efisien. Menurut Barber Johnson nilai AvLOS yang memenuhi standar adalah 3-12 hari.

Nilai TOI di RSUD Dr. Pirngadi Medan pada tahun 2018 adalah 9,51 hari. Hasil tersebut menunjukkan bahwa nilai TOI semakin besar dan belum efisien karena melebihi standar yang telah ditentukan oleh Barber Johnson yaitu 1-3 hari. Semakin besar angka TOI, berarti semakin lama tempat tidut tersebut tidak digunakan oleh pasien. Kondisi ini dapat merugikan pihak manajemen rumah sakit karena tidak menghasilkan pemasukan. Apabila nilai TOI semakin kecil, berarti tempat tidur tidak sempat disediakan dengan baik. Akibatnya, kejadian infeksi nosokomial bisa meningkat, beban kerja tim medis meningkat sehingga kepuasan dan keselamatan pasien dapat terancam (Sudra, 2010).

Nilai BTO di RSUD Dr. Pirngadi Medan pada tahun 2018 adalah 24,00 kali. Hasil tersebut menunjukkan bahwa nilai BTO masih rendah dan belum efisien karena belum memenuhi standar yang telah ditentukan oleh Barber Johnson yaitu minimal 30 kali. Semakin rendah nilai BTO, berarti hanya sedikit pasien yang menggunakan setiap tempat tidur dan semakin banyak tempat tidur yang tidak terpakai. Sehingga tempat tidur yang telah disediakan tidak dapat menghasilkan pemasukan secara aktif bagi rumah sakit. Apabila nilai BTO semakin tinggi berarti setiap tempat tidur digunakan oleh banyak pasien secara bergantian sehingga tempat tidur tidak sempat dibersihkan atau disterilkan. Kondisi tersebut dapat menimbulkan ketidakpuasan pasien, mengancam keselamatan pasien (patientsafety) serta dapat meningkatkan kejadian nosokomial (Sudra, 2010).

RSUD Dr. Pirngadi Medan merupakan rumah sakit tipe $\mathrm{B}$. Penggunaan tempat tidur di RSUD Dr. Pirngadi Medan masih belum efisien dikarenakan jumlah pasien yang sedikit dan faktor sistem BPJS (Badan Penyelenggara Jaminan Kesehatan). BPJS kesehatan menganut pola rujukan berjenjang, sehingga pasien tidak bisa bebas memeriksakan kesehatan ke rumah sakit atau faskes (fasilitas kesehatan) yang diinginkan. Pertama, pasien harus berobat ke faskes pertama yaitu puskesmas, klinik, atau dokter praktek yang bekerja sama dengan BPJS. Kemudian, jika faskes pertama tidak sanggup mengobati atau memerlukan pelayanan lanjutan oleh spesialis, maka akan dirujuk ke faskes yang lebih tinggi yaitu rumah sakit tipe $C$ lalu dapat dirujuk ke rumah sakit tipe B (BPJS, 2014).

\section{KESIMPULAN}

Dari hasil penelitian yang dilakuan oleh peneliti didapatkan kesimpulan sebagai berikut:

1. Nilai BOR di RSUD Dr. Pirngadi Medan pada tahun 2018 adalah 37,50\%. Nilai BOR tidak memenuhi standar ideal berdasarkan Barber Johnson yaitu 75$85 \%$.

2. Nilai AvLOS di RSUD Dr. Pirngadi Medan pada tahun 2018 adalah 5,36 hari. Nilai AvLOS sudah memenuhi standar ideal berdasarkan Barber Johnson yaitu 3-12 hari.

3. Nilai TOI di RSUD Dr. Pirngadi Medan pada tahun 2018 adalah 9,51 hari. Nilai TOI tidak memenuhi standar ideal berdasarkan Barber Johnson yaitu 1-3 hari.

4. Nilai BTO di RSUD Dr. Pirngadi Medan pada tahun 2018 adalah 24,00 kali. Nilai BOR tidak memenuhi standar ideal 
berdasarkan Barber Johnson yaitu minimal 30 kali.

5. Berdasarkan grafik Barber Johnson, penggunaan tempat tidur di RSUD Dr. Pirngadi Medan masih belum efisien karena titik Barber Johnson berada di luar daerah efisien.

\section{SARAN}

1. Bagi Rumah Sakit

a. Memperhatikan kembali rumus yang digunakan dalam menghitung nilai BOR, AvLOS, TOI dan BTO.

b. Membuat grafik Barber Johnson secara rutin minimal satu tahun sekali sehingga dapat meningkatkan efesiensi dan efektifitas penggunaan tempat tidur di ruang rawat inap serta sebagai strategi perencanaan di tahun berikutnya.

\section{DAFTAR PUSTAKA}

BPJS Kesehatan. (2014). Panduan Praktis Sistem Rujukan Berjenjang. Jakarta:
Badan Penyelenggara Jaminan Sosial Kesehatan.

Menteri Kesehatan RI. (2010). Keputusan Menteri Kesehatan RI No. 340/MENKES/PER/III/2010, Klasifikasi Rumah Sakit. Jakarta: Kemenkes RI.

Jannah, Azharatul. (2016). Analisis Penilaian Efisiensi Penggunaan Tempat Tidur Ruang Rawat Inap RSUD Tipe B di Kota Makassar Tahun 2016. Skripsi. Makassar: UIN Alauddin Makassar.

Pretty, Vivi. (2018). Gambaran Efisiensi Pelayanan Rawat Inap Berdasarkan Grafik Barber Johnson di RSUD Doloksanggul Kabupaten humbang Hasundutan Tahun 2017. Skripsi. Medan: Universitas Sumatera Utara.

Rustiyanto, Ery. (2010). Statistik Rumah Sakit Untuk Pengambilan Keputusan. Yogyakarta: Graha Ilmu.

Sudra, R. I. (2010). Statistik Rumah Sakit Dari Sensus Pasien \& Grafik BarberJohnson Hingga Statistika Kematian \& Otopsi. Yogyakarta: Graha Ilmu. 